\title{
The effect of structured consent on recall of information pre- and post-electroconvulsive therapy: a pilot study
}

\author{
J. Greening, P. Bentham, J. Stemman, V. Staples, S. Ambegaokar, \\ $R$. Upthegrove and E. Day
}

\begin{abstract}
Alms and method A randomised, blind comparison of a structured consent procedure against routine consent was conducted to determine whether it had any utility in improving treatment knowledge in patients recelving electroconvulsive therapy (ECD). Additionally we aimed to determine whether degree of cognitive impairment, intelligence and severtity of depression influenced recall of information.

Recults Thirty-two subjects were investigated. Structured consent significantly improved the number of knowledge items recalled pre-ECT $(P<0.05)$. Knowledge scores declined significantly after completion of the treatment course in both structured consent $(P<0.05)$ and control groups $(P<0.05)$. There was a significant correlation between Mini-Mental State Examination (MMSE) scores and the number of knowledge items recalled both pre- $(r=0.43, P<0.05)$ and post-ECT $(r=0.53, P<0.01)$.

Cinical implications Structured consent procedures may be a useful way of improving patient knowledge of ECT and merit further study. Low scores on MMSE should caution clinicians to take particular care when consenting patients to ECT.
\end{abstract}

In order to give informed consent to electroconvulsive therapy (ECT) a patient must be given adequate information about the treatment. He or she must also have the capacity to understand the nature, purpose and likely consequences of the treatment and be able to make a decision as to whether they wish to have it. In a study by Freeman \& Kendell (1980) conducted one year after ECT almost one-half of all patients said that they had received no explanation prior to treatment. Other studies have shown that patients have very poor understanding of the essential elements of ECT even before starting treatment (Malcolm, 1989).

There are several potential explanations as to why consent information is poorly recalled after
ECT. ECT can cause impairment of memory (Weeks et al, 1980) as can other forms of treatment, particularly tricyclic antidepressants (Thompson, 1991). Importantly depressive illness itself can impair memory (McAllister, 1981) and may substantially contribute to the problem.

Learning information can be improved by a number of simple techniques including: giving simple specific information; encouraging organisation and rehearsal; adding meaning to the material to be learned and by combining visual and verbal imagery (Baddeley, 1990).

This study aimed to determine whether utilising a structured consent procedure would enable patients to recall more treatment-related information both before and after a course of ECT compared with the standard consent procedure. We also aimed to determine whether degree of cognitive impairment, intelligence and severity of depression at the time of consent influence recall of this information.

\section{The study}

The study protocol had Local Research Ethics Committee approval. Subjects were recruited from patients referred for ECT at the Queen Elizabeth Psychiatric Hospital, Birmingham. Wards were telephoned daily to identify patients who fulfilled the following entry criteria: aged over 18 years, suffering from depressive lliness as defined by ICD-10 (World Health Organization, 1992) criteria; speaking English as their first language and informal status. Patients received an information sheet describing the study. including the right to withdraw and gave written consent prior to randomisation. Subjects were randomised using a sealed envelope technique to receive either structured consent from one of the investigators (J.G.) or to undergo the routine consent procedure administered by their 
own doctor. Both groups were given copies of the Royal College of Psychiatrists ECT information leaflet. Prior to ECT all subjects were assessed with the Montgomery-Ásberg Depression Rating Scale (MADRS; Montgomery \& Äsberg, 1979) the Mini-Mental State Examination (MMSE; Folstein et al, 1975) and the National Adult Reading Test (NART; Nelson \& Willison, 1991).

The structured consent procedure consisted of giving the subject 10 basic, important items of information about ECT drawn from the College information leaflet. The information took the form of short, specific verbal and written statements given simultaneously with a pictorial representation of the concept (e.g. memory loss - elephant with knotted trunkl). Subjects were then asked to recall the information they had been given. If fewer than 10 items were recalled subjects were selectively reminded of the missing items again using the same technique. This process was repeated to a total of three trials or until all 10 items were successfully recalled.

A questionnaire was administered on the morning of ECT to ascertain the subject's knowledge of the procedure before commencing ECT. This questionnaire was administered by an independent rater blind to the consent procedure. Subjects were asked what they knew about ECT and were then prompted by 14 questions drawn from the College information leaflet. Scoring was based on their ability to recall 20 target items of information taken from the same leaflet. An interrater reliability study utilising four raters produced a generalised Cohen's kappa value of 0.882 for the 20 items (range $k=0.815-0.925$ ).

Subjects were anaesthetised using methohexitone and suxamethonium. Atropine was not given. Treatment was administered using a Thymatron-DGX constant current ECT machine utilising a moderately supra-threshold stimulus.

Subjects were re-interviewed 1-7 days following completion of the ECT course using the same questionnaire. Details of the ECT course were also recorded.
The significance of between group differences were determined using independent $t$-tests for normally distributed data (comparing group means) and the Mann-Whitney test for nonparametric data (comparing group medians). Differences within groups, before and after ECT were analysed using the appropriate paired versions of these tests. Correlations were calculated using the Spearman method.

\section{The findings}

Thirty-two subjects entered the study, 21 female and nine male with a mean age of 55 years (range 20-84 years). Twenty-one subjects had a diagnosis of recurrent depresstve disorder, six of depresstve episode and five of bipolar affective disorder currently depressed. Twenty-six subjects were taking antidepressant medication, nine lithium, three carbamazepine, 19 were taking antipsychotic drugs and seven benzodiazepines.

The subjects had a mean MADRS score of $\mathbf{3 4 . 5}$ (range 19-56). Twenty-seven completed the NART with a mean IQ of 104.6 (range 86-123). The mean MMSE was 26.5 (range 21-30). Sixteen subjects were randomly allocated to structured consent and 16 to routine consent. The groups did not significantly differ on any of these measures (see Table 1). Two subjects withdrew consent prior to treatment, one absconded after a single treatment and a further subject's ECT course was terminated after two treatments because of a pulmonary embolus. Twenty-eight subjects completed a full course of ECT. The median course length was nine treatments (range 4-19) and the groups did not significantly differ in the number of treatments recetved (see Table 1). Twenty-six subjects had bilateral ECT, one unilateral and one a mixed course. Post-ECT evaluations were unavailable on four subjects due to early discharge or transfer to medical wards.

The mean number of items recalled pre-ECT by the structured consent group (9.4) was significantly greater than in the control group (6.4;

Table 1. Comparison of baseline and treatment characteristics between routine and structured consent groups receiving electroconvulsive therapy (ECD)

\begin{tabular}{lllll}
\hline & $\begin{array}{l}\text { Routine consent } \\
\text { group }\end{array}$ & $\begin{array}{l}\text { Structured consent } \\
\text { group }\end{array}$ & Statistic (d.f.) & Probability \\
\hline Median age in years (range), $n=32$ & $67.5(20-84)$ & $58.5(24-83)$ & $U=120.5$ & $P=0.78$ \\
Median ECT number (range) $n=28$ & $9.0(5-12)$ & $8.0(4-19)$ & $U=83.0$ & $P=0.51$ \\
Mean MADRS score (s.d.) $n=31$ & $37.4(9.2)$ & $31.8(8.3)$ & $t=1.795$ (d.f.=29) & $P=0.08$ \\
Mean NART IQ score (s.d.) $n=28$ & $102.4(11.2)$ & $106.9(11.2)$ & $t=-1.08$ (d.f.=26) & $P=0.29$ \\
Mean MMSE score (s.d.) $n=31$ & $25.5(3.1)$ & $27.4(2.4)$ & $t=-1.96$ (d.f.=29) & $P=0.06$ \\
\hline
\end{tabular}

MADRS, Montgomery-Ȧsberg Depression Rating Scale (Montgomery \& Ásberg. 1979); NART, National Adult Reading Test (Nelson \& Willison, 1991); MMSE, MinitMental State Examination (Folstein et al, 1975). 
Table 2. Comparison of number of knowledge items recalled pre- and postelectroconvulsive therapy (ECD) between normal and structured consent groups

\begin{tabular}{|c|c|c|c|c|}
\hline & $\begin{array}{l}\text { Routine consent } \\
\text { group }\end{array}$ & $\begin{array}{l}\text { Structured consent } \\
\text { group }\end{array}$ & Statistic & Probabillity \\
\hline $\begin{array}{l}\text { Mean number of tiems recalled } \\
\text { pre-ECT, } n=29\end{array}$ & 6.4 (s.d. 2.97) & 9.4 (s.d. 4.45 ) & $t=-2.14(d . f .=27)$ & $P=0.04$ \\
\hline $\begin{array}{l}\text { Median number of items recalled } \\
\text { post-ECT, } n=24\end{array}$ & 4.0 (range 0-12) & 8.0 (range 1-12) & $U=42.5$ & $P=0.11$ \\
\hline
\end{tabular}

$P<0.05)$, there was however no significant postECT difference in the median number of items recalled between the structured consent group (eight) and the control group (four; see Table 2).

Within the structured consent group the mean number of items recalled post-ECT (6.91) was significantly lower than before the treatment (9.4; $t=2.950$, d.f. $=7, P<0.05$ ), similarly within the control group the mean number of items recalled post-ECT (4.6) was significantly lower $(t=2.602$, d.f. $=12, P<0.05)$ than pre-ECT (6.4).

There was a posittve correlation between MMSE scores and number of knowledge items recalled both pre-ECT $(r=0.43, P<0.05)$ and post-ECT $(r=0.53, P<0.01)$. In contrast there was no significant correlation between either MADRS or NART IQ scores and number of knowledge items recalled pre-ECT or post-ECT. There was however a significant negative correlation between the number of ECT treatments received and the number of knowledge items recalled at the end of the course ( $r=-0.57, P<0.005$; see Table 3 ).

\section{Comment}

The results support the hypothesis that a structured consent procedure can significantly improve patient understanding of ECT prior to treatment. The difference in median number of items recalled post-ECT did not reach significance but could have been due to a type-2 error. It has been shown that simple information leaflets can improve knowledge in patients receiving ECT (Jenaway, 1993) but this variable had been accounted for as both groups received the College ECT information leaflet. The signifi- cant decline in knowledge scores and the significant negative correlation with the number of ECT treatments received could be taken as evidence that ECT has a deleterious effect on memory. The magnitude of decline was not unduly large, however, as patients typically forget half of the information given to them by doctors (Ley, 1988) and patients recetving longer courses of ECT have a longer time to forget. As treatment knowledge declines over a course of ECT doctors should consider consent issues when reviewing the need for further treatment.

Patients are assumed to have capacity until proven otherwise, but this should not be simply judged on the basis as to whether they say yes' when asked if they have understood the information and wish to have the treatment. Elderly patients in particular appear to have a great faith in doctors acting in their best interest and may feel less able to refuse ECT (Malcolm, 1989). It was conspicuous that several patients in the structured consent group were prepared to consent before they had even a basic understanding of the treatment. MMSE scores were significantly correlated with knowledge recall both before and after ECT. In contrast there was no significant association with severity of depression and estimated pre-morbid 1Q. The MMSE is commonly used to screen for cognittve impairment and scores of 23 and below should alert the clinician to the possibility that a patient may lack capacity to consent to treatment. In this situation particular care should be taken when giving information and it would be prudent to specifically question the patient on their level of understanding.

Table 3. Spearman correlation coefficients between factors potentially affecting cognition and recall of knowledge items pre-and post-electroconvulsive therapy (ECT)

\begin{tabular}{|c|c|c|c|c|}
\hline & \multicolumn{2}{|l|}{ Pre-ECT } & \multicolumn{2}{|l|}{ Post-ECT } \\
\hline & Correlation & Probcbllity & Correlation & Probabllity \\
\hline $\begin{array}{l}\text { Mini-Mental State Examination } \\
\text { Montgomery-Ásberg Depression Rating Scale } \\
\text { National Adult Reading Test } 1 Q \\
\text { ECT number }\end{array}$ & $\begin{array}{l}r=0.434(n=28) \\
r=0.131(n=28) \\
r=0.317(n=25)\end{array}$ & $\begin{array}{l}P=0.021 \\
P=0.507 \\
P=0.122\end{array}$ & $\begin{array}{l}r=0.530(n=23) \\
r=0.185(n=23) \\
r=0.402(n=22) \\
r=-0.57(n=23)\end{array}$ & $\begin{array}{l}P=0.009 \\
P=0.398 \\
P=0.064 \\
P=0.005\end{array}$ \\
\hline
\end{tabular}

Mini-Mental State Examination (Folstein et al, 1975); Montgomery-Äsberg Depresston Rating Scale (Montgomery \& Ásberg. 1979); National Adult Reading Test (Nelson \& Willison, 1991). 
The study's pilot design has several limitations. The sample size was small and excluded detained patients. A substantial number of dropouts occurred, but these were not excessive in light of the sample's morbidity. The sealed envelope technique is a simple, though not entirely reliable method of randomisation, but it produced broadly comparable groups. It is uncertain whether improved knowledge scores were specifically due to the structured consent process as enthusiasm and time spent were not adequately controlled for, however pre-ECT, $87 \%$ of the control group patients were satisfied with the information received. Multiple raters were used but the questionnaire demonstrated good inter-rater reliability on a stringent measure.

We feel that a further study is justified and allowing for drop-outs, it is estimated that approximately 50 patients in each group would be required to give the study $80 \%$ power to detect a two-point difference in knowledge scores postECT between structured and routine consent procedures at a $5 \%$ level.

\section{Acknowledgement}

Sincere thanks to Dr M. S. Haque, Statistician, Queen Elizabeth Psychiatric Hospital Research and Development Unit for advice and assistance with the statistical analysis.

\section{References}

BAdDeley, A. (1990) Human Memory Theory and Practice. Hove: LEA.

Freeman, C. P. L. \& Kendeul, R. E. (1980) ECT: I. Patients' experiences and attitudes. Brittsh Joumal of Psychiatry. 137. 8-16.
Folstein, M., Folstein, S. \& McHugh, P. (1975) Mini Mental State - a practical method for grading the cognittve state of patients for the clinician. Joumal of Psychiatric Research, 12, 189-198.

JENAWAY, A. (1993) Educating patients and relatives about electroconvulstive therapy: the use of an information leaflet. Psychiatric Bulletin. 17, 10-12.

LEY, P. (1988) Communicating with Pattents. London: Croom Helm.

MALCOLM, K. (1989) Patients' perceptions and knowledge of electroconvulstve therapy. Psychiatric Bulletin, 13. 161165.

MCALUSTER, T. W. (1981) Cognitive functioning in the affective disorders. Comprehenstue Psychiatry. 22. 572-586.

Montgomery, S. A. \& Ásberg, M. (1979) A new depression scale designed to be sensittve to change. British Joumal of Psychiatry, 134, 382-389.

Nelson, H. E. \& Wuuson, J. R. (1991) National Adult Reading Test (NART): Test Manual (2nd edn). Windsor: NFER-Nelson.

THOMPSON, P. J. (1991) Antidepressants and memory: a review. Human Psychopharmacology, 6, 79-90.

WeEKS, D. FREEMAN, C. P. L. \& KENDELL, R. E. (1980) ECT: III. Enduring cognitive deficits? Brittsh Joumal of Psychiatry, 137, 26-37.

WORLD HEALTH ORganization (1992) The Tenth Revision of the International Classification of Diseases and Related Health Problems (ICD-10). Geneva: WHO.

J. Greening, Senior House Officer, All Birmingham Psychiatry Rotational Training Scheme; ${ }^{*} \mathrm{P}$. Bentham, Consultant in Old Age Psychiatry. The Queen Elizabeth Psychiatric Hospital, Edgebaston, Birmingham B15 2QZ; J. Stemman, Specialist Registrar, V. Staples, Specialist Registrar, West Midlands Higher Training Scheme in Psychiatry: S. Ambegaoker, Senior House Officer, R. Upthegrove, Senior House Officer, E. Day, Senior House Officer, All Birmingham Psychiatry Rotational Training Scheme

*Correspondence

\title{
Onset of clinical improvement of depressive illness following electroconvulsive therapy
}

\author{
L. Ogundipe, M. Jorsh, B. Wain and J. Lea
}

Aims and method To examine the onset and course of clinically observable improvement in patients recelving electroconvulsive therapy (ECD). A prospective design was used in which 19 consecutive patients recelving ECT were followed up from commencement to termination of ECT. The Clinical Global Improvement 